\title{
Efeito da incorporação no solo de sementes de fedegoso (Senna obtusifolia) colonizadas por Alternaria cassiae no controle desta planta infestante
}

\author{
Fernanda De Simoni ${ }^{1}$, Robinson Luiz Campos Machado Pitelli², Robinson Antonio Pitelli ${ }^{3}$
}

'Pós-graduanda de Mestrado em Fitotecnia - Escola Superior de Agricultura “Luiz de Queiroz" - Departamento de Produção Vegetal. Universidade de São Paulo; ${ }^{2}$ Pós-graduando de Doutorado - Faculdade de Ciências Agronômicas, Câmpus de Botucatu. Universidade Estadual Paulista; ${ }^{3}$ Prof. Titular da Faculdade de Ciências Agrárias e Veterinárias, Câmpus de Jaboticabal. Universidade Estadual Paulista. Via de acesso Prof. Paulo D. Castellane, s/n - CEP 14884-900 - Jaboticabal - SP.

Data de chegada: 04/04/2004. Aceito para publicação em: 26/08/2005.

\begin{abstract}
Simoni, F.; Pitelli, R.L.C.M.; Pitelli, R.A. Effects of soil incorporation of sicklepod (Senna obtusifolia) seeds colonized of Alternaria cassiae on the control this weed. Summa Phytopathologica, v.32, n.4, p.367-372, 2006.

In the last decade, the excessive use of chemical control resulted in changes in the weed communities, which led to strong shifting in their population and finally in resistance to several herbicides. This is a very good opportunity to use biological management as a complementary method to control the selected weeds. Sicklepod seeds colonized by Alternaria cassiae were amended to the soil to control Senna obtusifolia plants. Two experiments were conducted under greenhouse conditions, where the colonized seeds (inoculum) were applied to the soil by dispersal over its surface and incorporation in the $2-3 \mathrm{~cm}$ layer. After fungal application, S. obtusifolia seeds previously scarified with sulfuric acid were sown in pots. The experimental design was the completely

randomized with four replications. A factorial arrangement of treatments was used and the variables were: a) two granulations of inoculum (whole and chopped colonized seeds); b) four inoculum concentrations (10, 6.5, 3.3 , and $1.7 \mathrm{ton} / \mathrm{ha})$; c) control plot without any inoculum incorporation. The evaluated parameter were counting of the number of emerged plants and weighing of dry matter accumulation in the aerial and roots tissues of the reminiscent plants. In both trials, there was a tendency to reduce the number of reminiscent plants and of the dry matter accumulation at aerial parts, as the amount of inoculum was increased. There were not important differences between the inoculum constituted by whole or chopped seeds.
\end{abstract}

Additional keywords: weed, biological control, micoherbicide, Senna obtusifolia, Alternaria cassiae

\section{RESUMO}

Simoni, F.; Pitelli, R.L.C.M.; Pitelli, R.A. Efeito da incorporação no solo de sementes de fedegoso (Senna obtusifolia) colonizadas por Alternaria cassiae no controle desta planta infestante. Summa Phytopathologica, v.32, n.4, p.367-372, 2006.

$\mathrm{Na}$ última década, com o uso excessivo de herbicidas, começaram a surgir alguns problemas como a resistência de plantas daninhas e seleção de flora, além do acúmulo destes produtos contaminando mananciais hídricos e solos. Como alternativa, há uma tendência recente em se estudar e desenvolver inimigos naturais para o controle das plantas daninhas, ou seja, o controle biológico. Sementes de fedegoso colonizadas por Alternaria cassiae foram incorporadas no solo, visando o controle de plantas de Senna obtusifolia. Para tanto, foram instalados dois experimentos em casa-de-vegetação com vasos. A inoculação do solo dos vasos com posterior incorporação nos primeiros 2-3 cm superficiais foi efetuada com sementes colonizadas. Após incorporação, sementes íntegras de Senna obtusifolia, previamente escarificadas, foram semeadas no solo dos vasos. O delineamento experimental adotado foi inteiramente casualizado com quatro repetições adotando as seguintes variáveis: a) duas formas de inóculo (sementes inteiras e sementes moídas); b) quatro quantidades por unidade de área (10t/ha; 6,5t/ha; 3,3t/ha e $1,7 \mathrm{t} / \mathrm{ha}) ; \mathrm{c}$ ) testemunha sem incorporação de inóculo ao solo. Os parâmetros avaliados foram, contagem do número de plantas emergidas e pesagem da matéria seca acumulada na parte aérea e do sistema radicular das plantas. Em ambos os experimentos, houve uma tendência de diminuição do número de plantas vivas, da biomassa seca da parte aérea e da matéria seca acumulada no sistema radicular à medida que foi aumentando a quantidade de inóculo incorporado no solo. Os efeitos de controle promovidos pelas duas formas de inóculo não diferiram expressivamente entre si.

Palavras-chave adicionais: planta daninha, controle biológico, micoherbicida, Senna obtusifolia, Alternaria cassiae. 


\section{INTRODUÇÃO}

Com a excessiva utilização de herbicidas que atuam em sítios muito específicos do metabolismo vegetal, começaram a aparecer as primeiras populações de plantas resistentes e seleção de flora, decorrentes da pressão de seleção promovida por herbicidas ou por um grupo de produtos com o mesmo modo de ação. Com isto, novas técnicas de controle têm sido estudadas em todo o mundo, visando reduzir a pressão de seleção. Durante toda a evolução da agricultura e das próprias plantas daninhas, houve a atuação constante de outra modalidade de controle, quase nunca percebida ou avaliada, o controle natural exercido pelos fatores ecológicos bióticos atuantes nos agroecossistemas. Os impactos das pressões bióticas do meio sobre as populações de plantas daninhas são pouco quantificados. No entanto, há uma tendência recente de se estudar e desenvolver estes inimigos naturais para o controle de plantas daninhas, ou seja, o controle biológico, como medida complementar aos métodos tradicionais.

São muitas as dificuldades para a implantação de programas de controle biológico de plantas daninhas, especialmente pela estratégia do bioherbicida. Uma delas é a grande especificidade dos inimigos naturais utilizados nesta técnica, especialmente nos climas tropicais e sub-tropicais onde as comunidades infestantes normalmente são altamente diversificadas. A simples eliminação de uma espécie teria pequeno efeito global. Outra limitação é a necessidade de grandes quantidades de inóculo para conseguir altas infectividade e virulência e, em conseqüência, bom nível de controle. O uso de um agente específico faz sentido para plantas selecionadas por um programa de controle amplamente empregado, como é o caso de plantas daninhas resistentes a herbicidas ou decorrentes de seleção de flora, como é o caso do fedegoso.

Considerando as modalidades de controle e herbicidas disponíveis para a cultura da soja, o fedegoso (Senna obtusifolia) é uma planta de difícil controle e vem sendo selecionada, formando densas infestações no sudeste dos EUA e oeste do estado do Mato Grosso do Sul (5). A cultura da soja é citada porque, no Brasil, é a única cultura em que esta planta daninha tem grande importância econômica, exatamente pela seleção promovida pelos herbicidas (6). Bozsa et al. (2) observaram perda de $30 \%$ na produção da soja pela interferência de 3,3 plantas de fedegoso por metro linear (próximo ao sulco da soja).

O fungo Alternaria cassiae Jurair \& Khan é considerado um candidato ideal para o desenvolvimento de um bioherbicida para controle de fedegoso (3). O isolado brasileiro deste fungo foi encontrado no estado do Rio Grande do Sul por Figueiredo et al.(4) e apresentou boa eficácia no controle de planta daninha. A patogenicidade de Alternaria cassiae já foi testada em 33 espécies vegetais, em condições de casa-de-vegetação e foi constatado que o fungo foi levemente patogênico apenas em S. obtusifolia, Crotalaria spectabilis e Cassia occidentalis.

Devido à grande dificuldade de produzir altas quantidades de esporos deste fungo, objetivou-se neste trabalho estudar o impacto da incorporação de sementes de fedegoso colonizadas pelo fungo no solo de vasos, visando o controle biológico desta planta daninha.

\section{MATERIAL E MÉTODOS}

\section{Produção de inóculo}

Cinqüenta gramas de sementes de Senna obtusifolia foram embebidas em $50 \mathrm{~mL}$ de água destilada e autoclavadas duas vezes, a $120^{\circ} \mathrm{C}$, por 20 minutos. Em cada frasco, contendo as sementes autoclavadas foi depositado um volume de $4,0 \mathrm{~mL}$ de suspensão $\left(10^{5}\right.$
conídios/mL) de Alternaria cassiae sobre as sementes, sendo posteriormente incubado sob condições de escuro total e temperatura ambiente. $\mathrm{O}$ isolado utilizado neste experimento foi proveniente do CENARGEN (EMBRAPA) sob o número de acesso CG593 e atualmente armazenado na micoteca do Laboratório de Controle Biológico de Plantas Daninhas "Prof. Giorgio de Marinis" da FCAV/ UNESP, Câmpus de Jaboticabal. Antes da inoculação do fungo, nas sementes autoclavadas, uma suspensão concentrada de conídios $\left(10^{6}\right.$ conídios $/ \mathrm{mL}$ ) foi pulverizada sobre plântulas de fedegoso e submetidas a 12 horas de câmara úmida. Após o aparecimento dos sintomas, foi realizado o re-isolamento do fungo, conferindo assim a patogenicidade do fungo e o Postulado de Kock.

Após completa colonização das sementes de fedegoso pela $A$. cassiae, a qual variou de quatro a sete dias, estas foram depositadas sobre bandejas de alumínio. As bandejas foram mantidas por cinco dias em sala climatizada $\left(21^{\circ} \mathrm{C}\right)$ para secagem. As sementes secas inteiras e/ou moídas em micro-moinho com peneira de $0,5 \mathrm{~mm}$ de abertura foram utilizadas como fonte de inóculo.

\section{Inoculação}

Vasos com volume de 1,0 L foram preenchidos com substrato constituído de terra, turfa e areia numa proporção de 3:1:1. A inoculação do solo dos vasos foi realizada mediante ao espalhamento do inóculo sobre a superfície com posterior incorporação nos primeiros $2-3 \mathrm{~cm}$ de profundidade. $\mathrm{O}$ delineamento experimental adotado foi o inteiramente casualizado com quatro repetições. Os tratamentos foram distribuídos num esquema fatorial $2 \times 4$, onde as variáveis foram: duas formas de inóculo de $A$. cassiae (sementes inteiras ou moídas) e quatro concentrações de inóculo [10 t/ha (15,0 g/vaso); 6,5 t/ha (10,0g/vaso); $3,3 \mathrm{t} / \mathrm{ha}(5,0 \mathrm{~g} /$ vaso $)$ e $1,7 \mathrm{t} / \mathrm{ha}(2,5 \mathrm{~g} /$ vaso $)]$. Adicionalmente, houve um tratamento testemunha sem a aplicação de inóculo no solo. Em cada vaso, foram transferidas 20 sementes de $S$. obtusifolia previamente escarificadas em ácido sulfúrico por cinco minutos. A irrigação dos vasos foi realizada por capilaridade, mediante a utilização de pratos plásticos colocados embaixo de cada vaso, sendo seu nível de água verificado e corrigido diariamente. As avaliações foram realizadas diariamente, através da contagem do número de plantas emergidas e mortas. Doze dias após a inoculação, as plantas remanescentes foram cuidadosamente retiradas inteiras do solo, visando avaliar a matéria seca acumulada na parte aérea e no sistema radicular.

\section{Análise dos Resultados}

Os dados coletados foram submetidos à análise de regressão, verificando o melhor ajuste ao modelo estatístico que poderia fornecer explicações biologicamente aceitáveis.

\section{RESULTADOS E DISCUSSÃO}

Os resultados obtidos com relação ao número de plantas vivas remanescentes e à matéria seca acumulada na parte aérea e no sistema radicular das plantas com 12 dias após a inoculação do fungo, estão apresentados nas figuras 1, 2, 3 e 4 . No primeiro experimento, observou-se um aumento no controle da planta daninha (número de plantas vivas) conforme aumento da dose de inóculo aplicado no solo. As plantas que sobreviveram ao período do experimento apresentaram reduções no acúmulo de matéria seca dos tecidos da parte aérea e do sistema radicular. Ambos os tipos de inóculo (inteiro e moído) causaram efeito inibitório no desenvolvimento da planta daninha. 

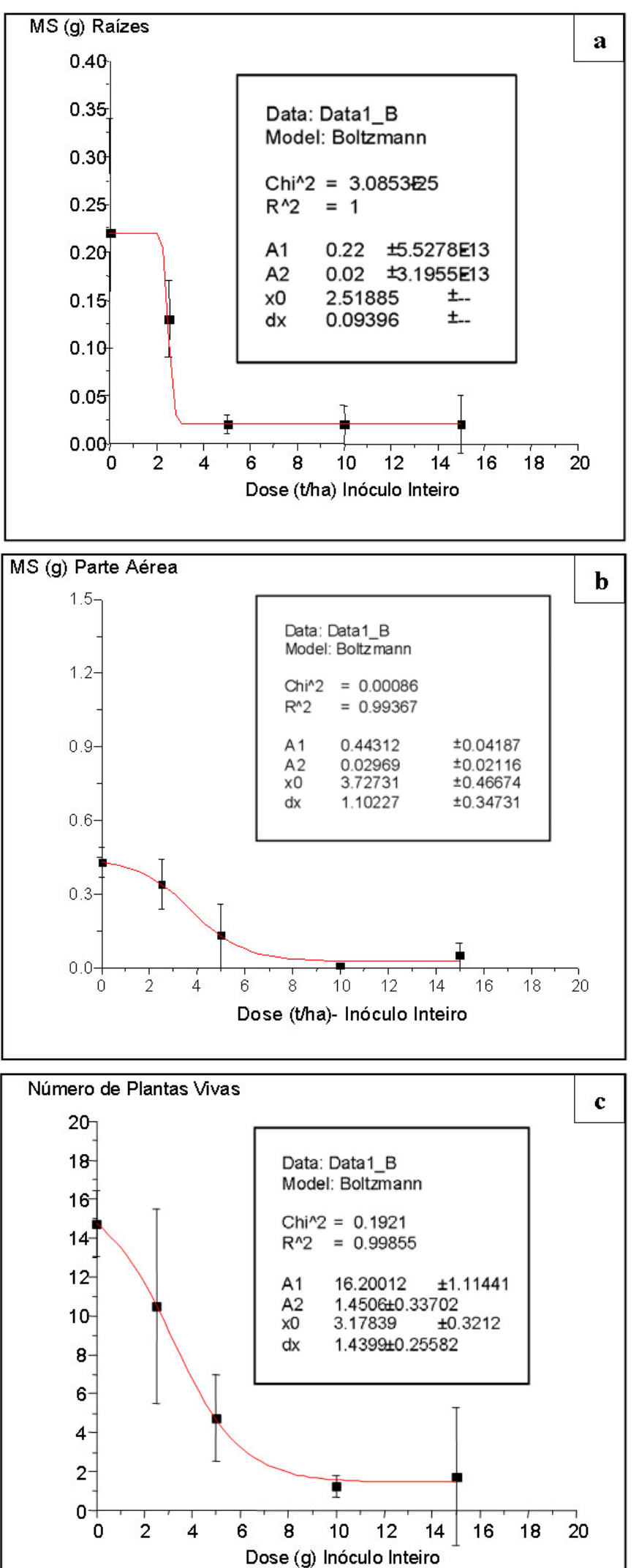

Figura 1 - Efeito das concentrações de inóculo inteiro do primeiro ensaio no número de plantas vivas remanescentes (c), na matéria seca acumulada nos tecidos aéreos (b) e no sistema radicular das plantas remanescentes (a) com 12 dias após a inoculação. As linhas verticais representam o desvio padrão da média dos dados.
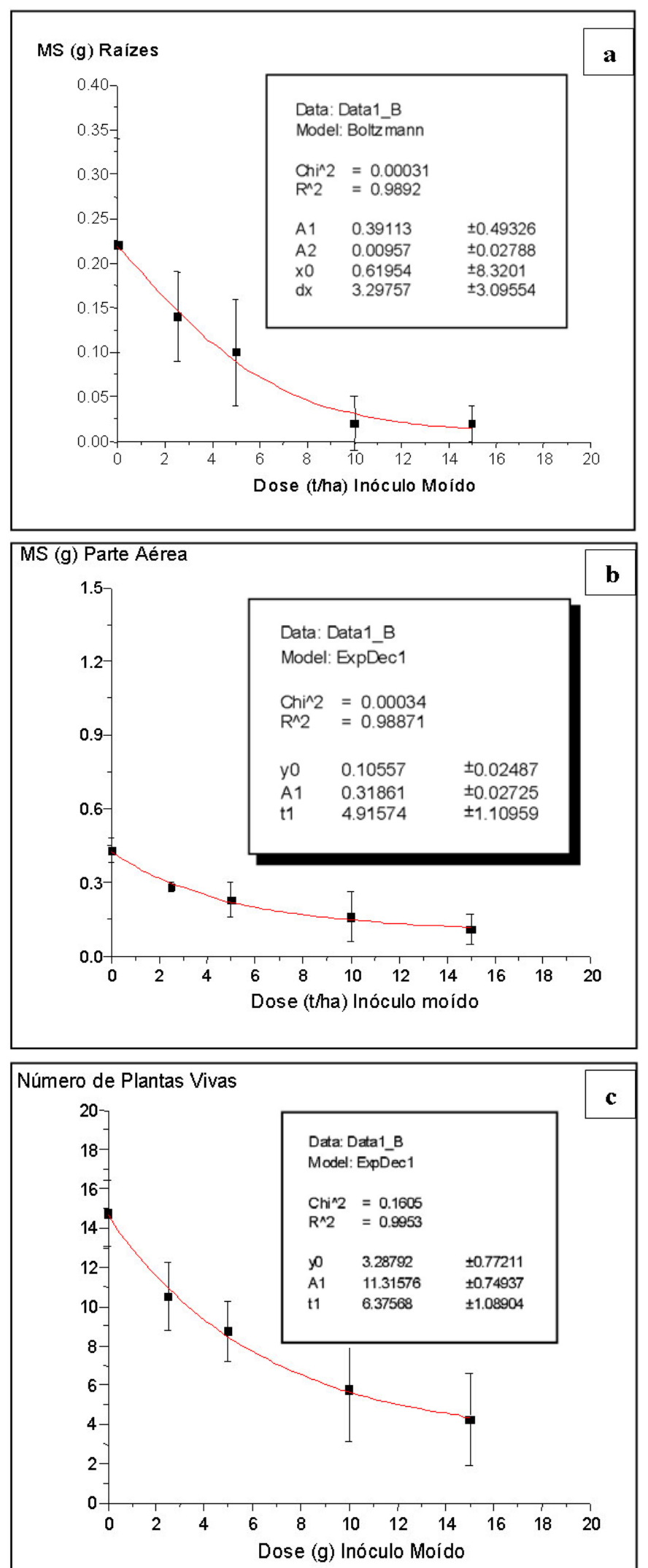

Figura 2 - Efeito das concentrações de inóculo moído do primeiro ensaio no número de plantas vivas remanescentes (c), na matéria seca acumulada nos tecidos aéreos (b) e no sistema radicular das plantas remanescentes (a) com 12 dias após a inoculação. As linhas verticais representam o desvio padrão da média dos dados. 

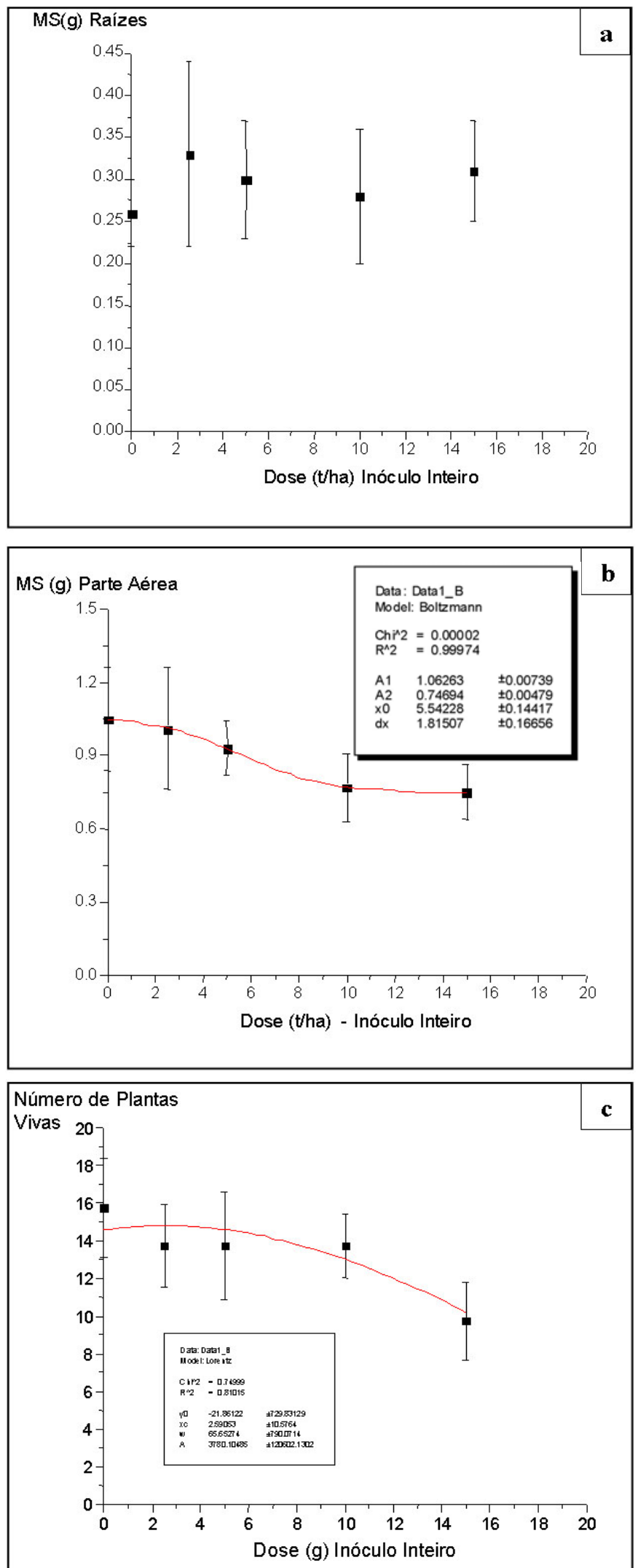

Figura 3 - Efeito das concentrações de inóculo inteiro do segundo ensaio no número de plantas vivas remanescentes (c), na matéria seca acumulada nos tecidos aéreos (b) e no sistema radicular das plantas remanescentes (a) com 12 dias após a inoculação. As linhas verticais representam o desvio padrão da média dos dados.
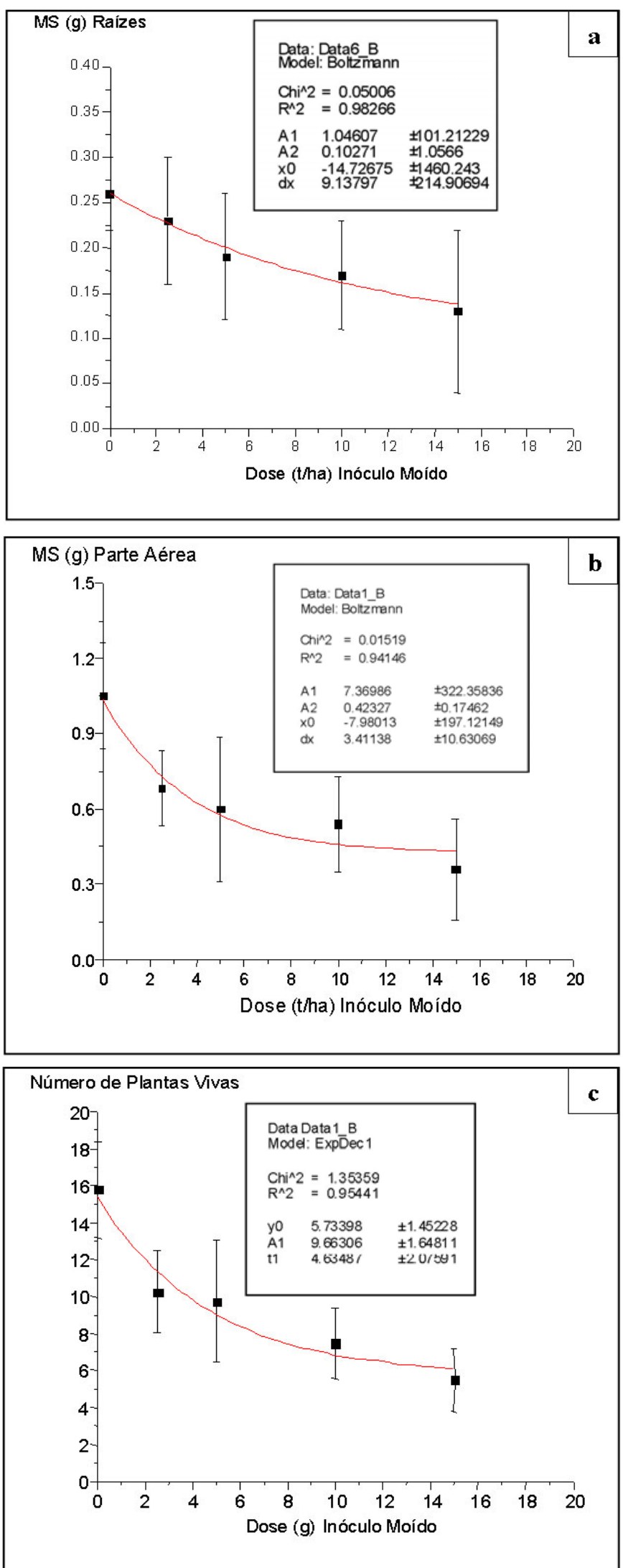

Figura 4 - Efeito das concentrações de inóculo moído do segundo ensaio no número de plantas vivas remanescentes (c), na matéria seca acumulada nos tecidos aéreos (b) e no sistema radicular das plantas remanescentes (a) com 12 dias após a inoculação. As linhas verticais representam o desvio padrão da média dos dados. 
No segundo experimento, o inóculo constituído por sementes inteiras colonizadas pelo fungo apresentou um efeito menos pronunciado sobre o desenvolvimento das plantas. Não foi observado um efeito inibitório expressivo sobre o número de plantas vivas remanescentes e na matéria seca acumulada nos tecidos da parte aérea. As diferentes doses de inóculo com sementes inteiras não causaram efeito sobre a matéria seca, acumulada no sistema radicular destas plantas. O inóculo constituído por sementes moídas apresentou tendência semelhante ao do primeiro experimento, mas com reduções menos acentuadas (Figura 5).

Apesar dos resultados do primeiro experimento demonstrarem alta eficácia do fungo cultivado em sementes de fedegoso, no controle da planta daninha, o mesmo não foi observado no segundo experimento, principalmente no inóculo constituído por sementes inteiras.
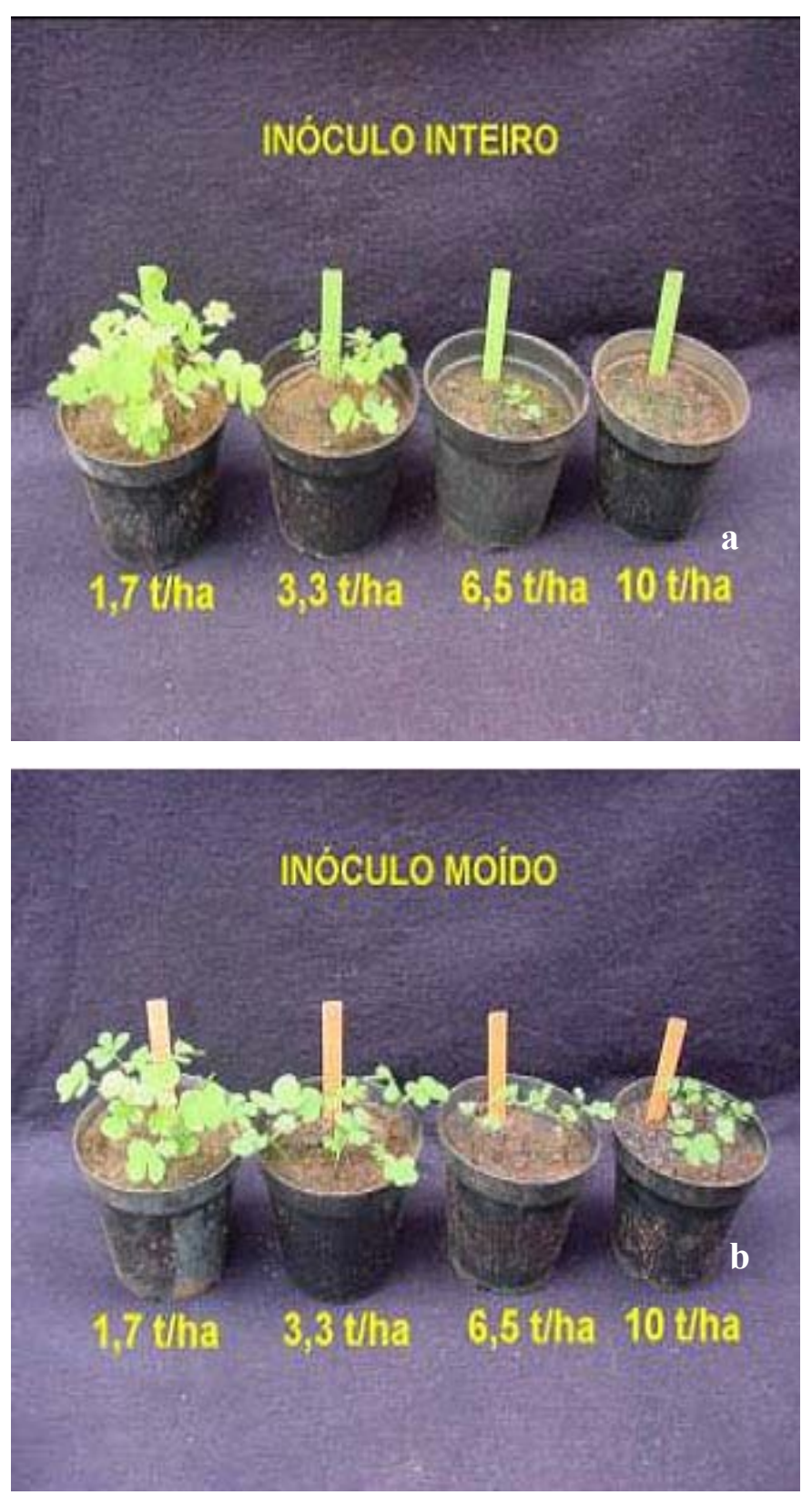

Figura 5 - Efeito das diferentes doses incorporadas no solo dos vasos, utilizando como inóculo sementes inteiras (a) e sementes moídas (b) colonizadas por Alternaria cassiae, no desenvolvimento das plantas de fedegoso (Senna obtusifolia), em condições de casa - de - vegetação.
Possivelmente este fato ocorreu devido a problemas ocorridos na distribuição do inóculo no solo ou na colonização das sementes pelo fungo, causando menor desenvolvimento micelial e, conseqüentemente, menor potencial de inóculo. Esta hipótese é, portanto, mais aceitável, sendo que não é uma certa concentração do fungo que se aplica no solo, mas sim uma certa concentração de substrato (sementes) que contém uma quantidade desconhecida e variável de micélio e conídio infectivo.

Não se encontra na literatura especializada, trabalhos relacionados a incorporação de sementes infectadas com agentes de controle biológico visando manejar plantas daninhas. Na préemergência, Walker \& Connik (10) demonstraram a viabilidade da utilização de formulação de "pellets" de alginato de sódio como fonte de inóculo contendo (Alternaria cassiae) para controlar fedegoso. No entanto, esta é uma condição muito diferente da utilizada neste trabalho, onde o inóculo foi constituído de micélio e conídio em sementes. Pitelli et al. (7) observaram que a incorporação direta de elevadas quantidades de esporos de $A$. cassiae no solo promove expressivo controle de plântulas de S. obtusifolia, por um período de 21 dias. A quantidade de inóculo utilizada neste trabalho foi de $10^{5}$ conídios por centímetro quadrado de superfície de solo, o que é inviável economicamente. Muitos trabalhos como de Charudattan et al. (3), Pitelli et al. (8) e Walker \& Riley (9) demonstram a eficácia no controle de plântulas de fedegoso pulverizada na sua parte aérea com suspensão de esporos. Levando em consideração a dificuldade existente na produção massal de esporos de $A$. cassiae, Ávila et al. (1) demonstrou outra forma de utilização do agente de controle biológico, que junto com as técnicas hoje utilizadas, poderá ser uma ferramenta importante num programa de manejo da população de plantas daninhas.

\section{AGRADECIMENTOS}

Ao CNPq pelo auxílio financeiro concedido para o Projeto, e ao livre acesso no Laboratório de Controle Biológico de Plantas Daninhas "Giorgio de Marinis", UNESP/Jaboticabal.

\section{REFERÊNCIAS BIBLIOGRÁFICAS}

1. Ávila, Z.R.; Mello, S.C.M.; Ribeiro, Z.M.A.; Fontes, E.M.G. Produção de inóculo de Alternaria cassiae. Pesquisa Agropecuária Brasileira, Brasília, v.35, n.3, p.533-541, 2000.

2. Bozsa, R.C.; Oliver, L.R.; Driver, T.L. Intraespecific and interespecific sicklepod (Cassia obtusifolia) interference. Weed Science, Champaign, v.37, p.670-673, 1989.

3. Charudattan, R.; Walker, H.L.; Boyette, C.D.; Ridings, W.H.; TeBeest, D.O.; Van Dyke, C.G.; Worshan, A.D. Evaluation of Alternaria cassiae as a mycoherbicide for sicklepod (Cassia obtusifolia) in regional field tests. Department of Research Information, Alabama. Agricultural Experimental Station, Auburn University, 1986. 19p.

4. Figueiredo, G.; Fontes, E.G.; Teixeira, C.A.D.; Pais, J.S. Levantamento e seleção de patógenos para o controle biológico de fedegoso (Senna obtusifolia: Leguminosae). Fitopatologia Brasileira, Brasília, v.17, p.169, 1992.

5. Lemus, E.A.E. Crescimento, nutrição mineral e resposta à calagem em Senna obtusifolia (L.) Irwin \& Barneby. 1994. 140p. Tese (Doutorado em Produção Vegetal) - Faculdade de Ciências Agrárias e Veterinária, Universidade Estadual Paulista, Jaboticabal. 
6. Pitelli, R.A. Weed-soybean interference studies in Brazil. In: COOPING, L.G.; GREEN, M.B.; REES, R.T. (Ed.). Pest management in soybean. London: Elsevier Science, 1992, p.282-289.

7. Pitelli, R.A.; Charudattan, R.; Devalerio, J.T. Biocontrol of sicklepod by preemergent soil-incorporation of Alternaria cassiae sp. In: American Phytopathological Society Annual Meeting, 34., 1993, Nashville-TE. 1993. p.78. (Abstract).

8. Pitelli, R.A.; Charudattan, R.; Devalerio, J.T. Effect of Alternaria cassiae, Pseudocercospora nigrigans, and soybean (Glycine max) planting density on the biological control of sicklepod (Senna obtusifolia). Weed Technology, Champaign, v.12, p.37-40, 1998.

9. Walker, H.L.; Riley, J.A. Evaluation of Alternaria cassiae for de biocontrol of sicklepod (Cassia obtusifolia). Weed Science, Champaign, v.30, p.651-654, 1982.

10. Walker, H. L.; Connick, W.J. Jr. Sodium alginate for production and formulation of mycoherbicides. Weed Science, Champaign, v.31, p.333-338, 1983. 